\title{
Large-scale force budget of an outlet glacier: Jutulstraumen, Dronning Maud Land, East Antarctica
}

\author{
G. Rolstad, ${ }^{1,2}$ I. M. Whillans, ${ }^{1}$ J. O. Hagen, ${ }^{2}$ E. Isaksson ${ }^{3}$ \\ ${ }^{1}$ Byrd Polar Research Center and Department of Geological Sciences, Ohio State University, Columbus, OH 43210-1308, U.S.A. \\ ${ }^{2}$ Department of Physical Geography, University of Oslo, P.O. Box 1042, Blindern, N-03116 Oslo, Norway \\ ${ }^{3}$ Norwegian Polar Institute, Norwegian Environmental Centre, N-9005 Tromsø, Norway
}

\begin{abstract}
A large-scale force budget was applied using a combination of remote-sensing and field data from Jutulstraumen, Dronning Maud Land, Antarctica. In the grounded area, more than $95 \%$ of ice flow is balanced by basal friction. In a partly floating section near the grounding-line area, on average lateral drag provides $38 \%$ of resistance to flow.

Measurement uncertainties were propagated through the calculation of forces. The accuracies of strain rates derived from satellite data (Landsat thematic mapper) were found adequate to calculate meaningful force-balance terms. For the floating section, where lateral forces contribute to controlling flow, the main contribution to errors in the force budget is uncertainty in the rate factor for the flow law of ice. For grounded sections, the uncertainty in ice thickness, as measured by ground-penetrating radar, contributes more or less equally to errors in the force budget as does that in the rate factor.
\end{abstract}

\section{INTRODUGTION}

An understanding of glacier motion can be gained from deductions of the balance of forces in existing glaciers (Whillans and Van der Veen, 1993, 1997). Here we conduct such an analysis of an outlet glacier in Antarctica using a dataset derived largely from repeat Landsat thematic mapper (TM) satellite images. An additional objective is to determine whether the existing dataset is adequate by considering propagation of measurement uncertainties through the force budget.

The particular application concerns the outlet glacier Jutulstraumen in Dronning Maud Land, East Antarctica. Information on its mechanics is needed for numerical modelling of ice-divide migration, and as part of the effort to provide a depth-age scale for the deep ice core to be drilled in 2000-05 for the European Project for Ice Coring in Antarctica (EPICA). Grounding-line position and ice dynamics on the seaward margin of a marine ice sheet are the most important unknowns when modelling divide migration at the interior of an ice sheet (Alley and Whillans, 1984). The main discharge from Dronning Maud Land is through Jutulstraumen (Fig. 1), which drains $124000 \mathrm{~km}^{2}$. This basin constitutes about $1 \%$ of the Antarctic ice sheet (Van Autenboer and Decleir, 1978). There exist few glaciological data for the glacier. In this paper we address the dynamics between the grounding-line area and $65 \mathrm{~km}$ up-glacier of Jutulstraumen.

Data on the glacier derive from satellite imagery and field measurements. Available data are velocities obtained by tracking of crevasses in repeated Landsat-TM satellite images. Strain rates were calculated from this velocity field and from interferometric synthetic-aperture radar (SAR). Bedrock was mapped using a ground-penetrating radar (Melvold and others, 1997; Näslund, 1997) along a longitudinal profile (profile 3, Fig. 2), and two transverse profiles (profile
1 and 2, Fig. 2). Profile 1 is located on the grounded part of the ice and profile 2 is near the grounding line. Precise global positioning system (GPS) measurements were used to collect four points of surface elevation along longitudinal profile 3 .

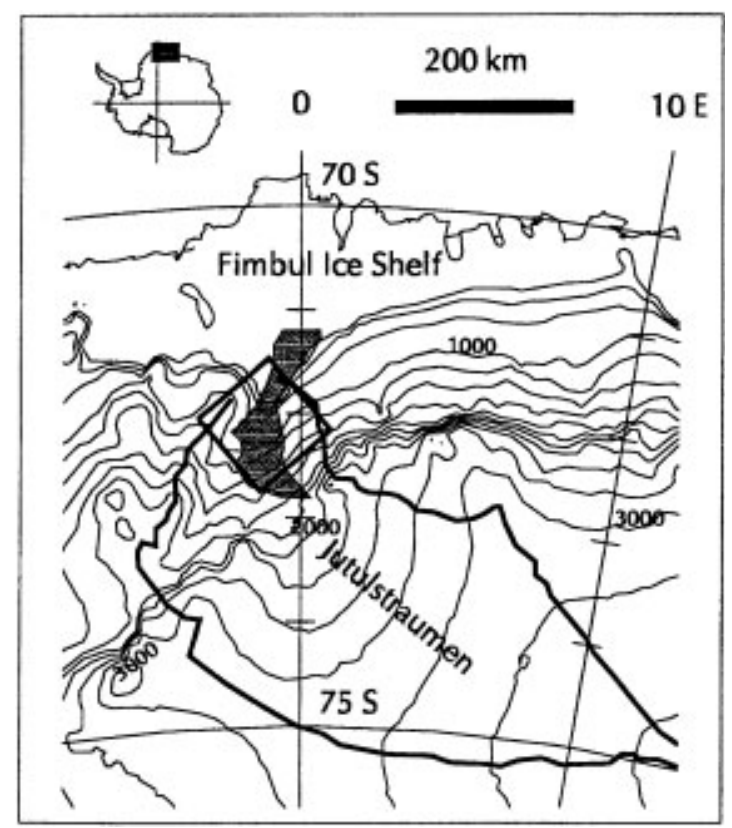

Fig. 1. Jutulstraumen, Dronning Maud Land $\left(75^{\circ} 30^{\prime} \mathrm{S}\right.$, $17^{\circ} \mathrm{E}$ to $70^{\circ} \mathrm{S}, 5^{\circ} \mathrm{W}$, from $100-3500 \mathrm{~m}$ a.s.l.). Elevations are from radar-altimeter data (Bamber and Bindschadler, 1997). Contour interval is $200 \mathrm{~m}$. Thick lines are boundaries of the drainage basin and the square is ERS-1 coverage ( $G$ phase, Frame 5679; orbit 13847, 10 March 1994 and orbit 13804, 7 March 1994). The grey area is where a velocity field was derived from Landsat-TM images (173/111-860124, 175/ 110 -850119, 175/111-850119), approximately at 72॰ $30^{\prime} \mathrm{S}$ from $1500 \mathrm{~m}$ a.s.l. to the ice shelf at $100 \mathrm{~m}$ a.s.l. 
The force budget was carried out for the three sections between these four points. Some velocity measurements are available from prior work. Orheim and Luchitta (1987) manually identified identical features in a Landsat multispectral scanner (MSS) scene from 1975 and a Landsat-TM

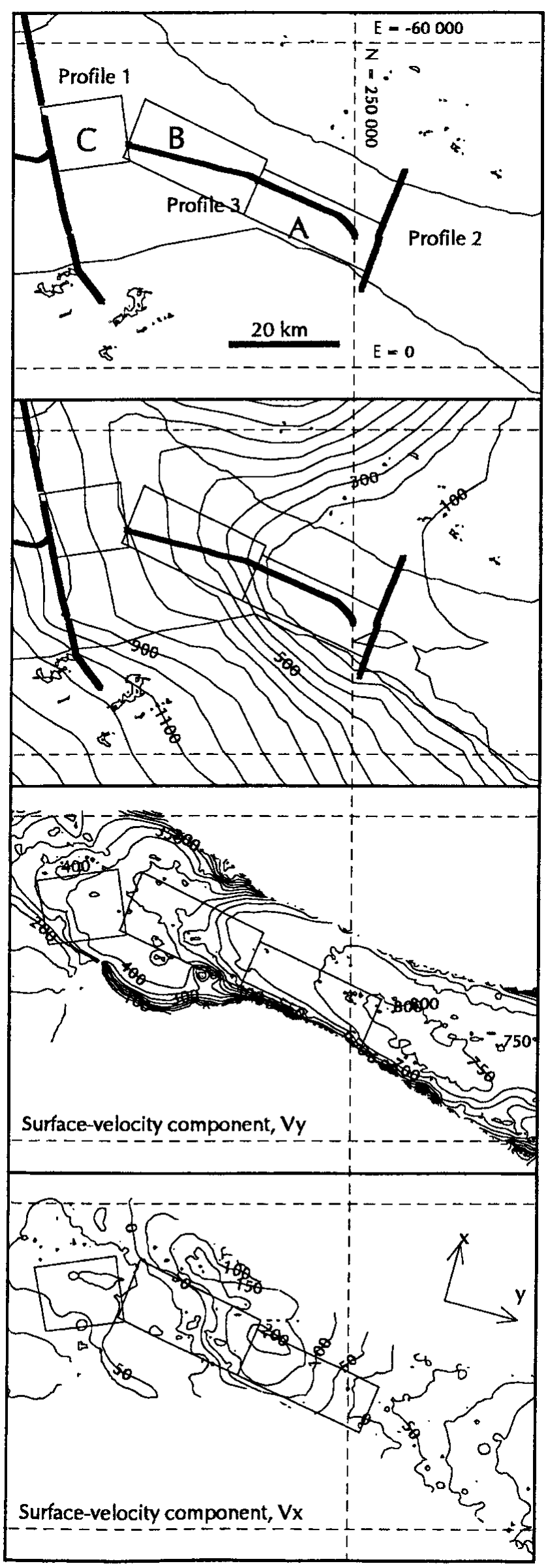

scene from 1985 covering the coastal areas of Jutulstraumen. Høydahl (1996) measured stakes along profile 1 and obtained similar results to Gjessing (1972).

\section{FORGE BUDGET}

Force-budget equations have been derived by many authors, including Van der Veen and Whillans (1989) who partitioned full stresses into lithostatic and resistive components. In this project, we use a simplified version by Whillans and Merry (in press). In this approach the forces acting on an imaginary large box in the glacier are assessed to find the relative importance of the forces in controlling ice flow in the box. The simplification is made that strain rates are equal to surface values at all depths, but that associated stresses are important only in the upper cold portion of the glacier. Force balance of a column through the glacier can be written for a righthand coordinate system were the $y$ axis is in the flow direction and the $x$ axis is in the transverse direction as:

$$
\tau_{\mathrm{d} y}=\tau_{\mathrm{b} y}-\frac{\partial}{\partial x}\left(H^{\prime} R_{y x}\right)-\frac{\partial}{\partial y}\left(H^{\prime} R_{y y}\right)
$$

where $\tau_{\mathrm{d} y}$ represents driving stress, $\tau_{\mathrm{b} y}$ is the basal drag, $H^{\prime}$ is the mechanically-effective ice-thickness, $R_{y x}$ is the lateral shear-stress and $R_{y y}$ is longitudinal tension. Stresses are considered for a box of dimensions $W$, width transverse to flow direction and $L$, length along flow. Integrating Equation (1) over the width and length, the budget of forces becomes

$$
\begin{aligned}
F_{\mathrm{d} y}=F_{\mathrm{b} y} & -\left[\left(W H^{\prime} R_{y y}\right)_{\text {down-glacier }}-\left(W H^{\prime} R_{y y}\right)_{\text {up-glacier }}\right] \\
- & {\left[\left(L H^{\prime} R_{x y}\right)_{\text {glacier_east }}-\left(L H^{\prime} R_{x y}\right)_{\text {glacier_west }}\right] }
\end{aligned}
$$

where $F_{\mathrm{d} y}$ is driving force;

$$
F_{\mathrm{d} y}=\iint_{\mathrm{LW}} \tau_{\mathrm{d} y} \mathrm{~d} y \mathrm{~d} x
$$

and $F_{\mathrm{b} y}$ is basal force. In subscripts are words indicating to which side of the box the quantities apply.

The stresses and forces on the sides of the box are calculated from strain rates derived from measured surface velocities. Glen's flow law is used in the simple format (without considering effective strain rates). Lateral shear stress acting on the along-flow sides is calculated from

$$
R_{y x}=B\left(\dot{\varepsilon}_{y x}\right)^{\frac{1}{n}} \text {. }
$$

In the shear margin, this simple formula is a good approxi-

Fig.2. Location of boxes and radar profiles, and surface elevations and glacier speed in the coastal area of Jutulstraumen. Flow direction is from left to right. All sections show the same area at the same scale. Coordinate axes in stippled lines in all sections are for a Lambert map projection. East (E) and north $(\mathcal{N})$ coordinates are shown in the upper section. Boxes for calculations of force budget are drawn in all sections. The upper section labels boxes $A, B$ and C. Ground-penetrating radar profiles are drawn with thick lines. Nunataks are shown with thin lines. The second section shows surface-elevation contours for each $100 \mathrm{~m}$ derived from radar-altimeter data (Bamber and Bindschadler, 1997). The two lower sections shows $x$ and $y$ components of glacier velocity derived from crevasse tracking in Landsat-TM images, with isotach interval each $50 m a^{-1}$. 
mation, because the effective shear stress is dominated by shearing. Longitudinal stress across the up- and down-glacier ends of the block is calculated using

$$
R_{y y}=2 B \dot{\varepsilon}_{y y}^{1 / n} .
$$

Here, lateral stretching, $\dot{\varepsilon}_{x x}$, is taken to be negligible, and indeed $\dot{\varepsilon}_{x x} \ll \dot{\varepsilon}_{y y}$. The neglect of the role of effective strain rate leads to values for $R_{y y}$ that are too small, but we learn below that these stresses play a very small role so inclusion of their effects is not a serious omission.

Strain rates derive from repeat satellite position measurements. Shear strain rate is calculated from

$$
\dot{\varepsilon}_{y x}=\frac{1}{2} \frac{\partial U_{y}}{\partial x},
$$

noting that $\partial U_{x} / \partial y \ll \partial U_{y} / \partial x$ so one may set $\partial U_{x} / \partial y=0$. Longitudinal strain rate is

$$
\dot{\varepsilon}_{y y}=\frac{\partial U_{y}}{\partial y} .
$$

Equations (4)-(7) are the expressions needed to calculate stresses from strain rates.

The driving stress is calculated from

$$
\tau_{\mathrm{d} y}=-\rho g H \frac{\partial h}{\partial y}
$$

where $\rho$ is ice density, $g$ is the acceleration of gravity and $h$ is surface elevation. The driving force is

$$
F_{\mathrm{d} y}=-\rho g \bar{H} \frac{\partial h}{\partial y} W L
$$

where $\bar{H}$ is average ice thickness.

Uncertainties in strain rates, stresses and forces were estimated using the theory of error propagation for statistical uncertainties (Bevington and Robinson, 1992). Estimated errors and inaccuracies in measurements are given as the standard deviation, $\sigma$, of the measurement.

\section{DATA}

Velocity and strain rates are derived from satellite images. Ice thickness and surface elevations were measured during the Norwegian Antarctic Research Expedition 1996-97.

\section{Landsat: velocity measurements by feature track- ing on repeat images}

The measurement method requires repeated observations of the same area. The displacement of a surface feature in the period between acquisition of the images is measured. The images must be geometrically correct, co-registered, and scaled to measure the exact displacement that has occurred on the ice surface.

\section{Rectification of Landsat images}

For Landsat-TM scenes the central projection along the scan lines places surface points with an elevation above sea level away from the projection centre in the image, and the displacement, $\Delta R$, increases with an increased incidence angle (Rolstad and others, 1997). The displacements were calculated as $\Delta R=(R / Z) \Delta Z$, where $R$ is radial distance to the terrain nadir, $Z$ is satellite elevation above a reference plane and $\Delta Z$ is terrain elevation above the reference plane.

For the Landsat-TM scenes, 16 well-distributed groundcontrol points (GCP) from the Norwegian Polar Institute's geodetic reference network were registered in the images to determine a transformation from image to map, involving scale, rotation and translation. The GCP image positions were reduced according to their elevation, and displacements as large as 7 pixels were calculated. The rms error of the transformation was reduced from 2.6 pixels to 0.9 pixels (28.5 $\mathrm{m}$ pixel size) by this approach. The image position for ground coordinates $X Y Z$ in the SCAR Antarctic digital elevation model (DEM) was calculated using the estimated transformation, together with the calculated image distortion due to elevation as obtained from the SCAR DEM. The images were then resampled to a $20 \mathrm{~m}$ pixel size. Locations on nunataks with known ground coordinates not used in the adjustment could be found in the resampled scene with an accuracy of $<1$ pixel (20 m pixels).

An image-to-image transformation for the oriented scene to an adjacent scene, covering the ice shelf without nunataks, was determined from 16 tie points in the overlap area $(\mathrm{rms}=$ $0.3,28.5 \mathrm{~m}$ pixel size). The adjacent scene was resampled according to the image-to-image and the image-to-map transformation, and calculated image distortions.

The one-year-separated image pair was coregistered using 10 well-distributed tie points on nunataks. Coregistration between the image pair improved significantly after the rectification, resulting in an rms error of 0.43 pixels (20 $\mathrm{m}$ pixels).

\section{Landsat image-to-image cross correlation}

A cross-correlation analysis was conducted on the pair of rectified coregistered Landsat-TM images from 1985-86 (Fig. 1). The correlation was estimated on a statistical basis using IMCORR software (Scambos and others, 1992). Correlation estimates were conducted on TM band 4 (near-infrared). The crevasse pattern was similar from year-to-year, yielding $>1000$ successful matches. Mismatched vectors were identified as those with a low correlation coefficient and these were excluded automatically in the IMCORR software. Vectors that deviated in direction or length from the surrounding vectors were identified on a monitor, and the mismatched vectors were removed (Bindschadler and others, 1996). The vectors remaining were interpolated to a grid using inverse-distance weighting interpolation.

\section{Results of the Landsat-determined velocity field}

The correlation of Landsat-TM images (from 1985 and 1986) was successful in the crevassed areas because the crevasse pattern had not changed during the period. Isotachs of speed, derived from the interpolated grid, are shown in Figure 2. The speed increases down-glacier, up to a maximum of $830 \mathrm{~m} \mathrm{a}^{-1}$ on the west side of Fimbul Ice Shelf. Near profile 2 the fastest speed, $800 \mathrm{~m} \mathrm{a}^{-1}$, is on the east side of the glacier. Orheim and Luchitta (1987) mapped 22 velocity vectors and also found the highest speed (for 1975-85) near the eastern side of profile 2, but the speed was only $744 \mathrm{~m} \mathrm{a}^{-1}$. The difference in speed in the two studies suggests a speed-up, but it can also be due to poorer spatial resolution in the multispectral-scanner image $(120 \mathrm{~m} / \mathrm{pixel})$ that used by Orheim and Luchitta.

Comparison of Landsat results with stake measurements and expected accuracy of velocity field

Høydal (1996) conducted GPS measurements of stakes with a 14 day repeat interval along transverse profile 1 (Fig. 3). The error in velocity was estimated to be $0.1 \%$ for the slowly moving stakes.

Our results along the profile were compared to Høydal's 19 
Profile 1

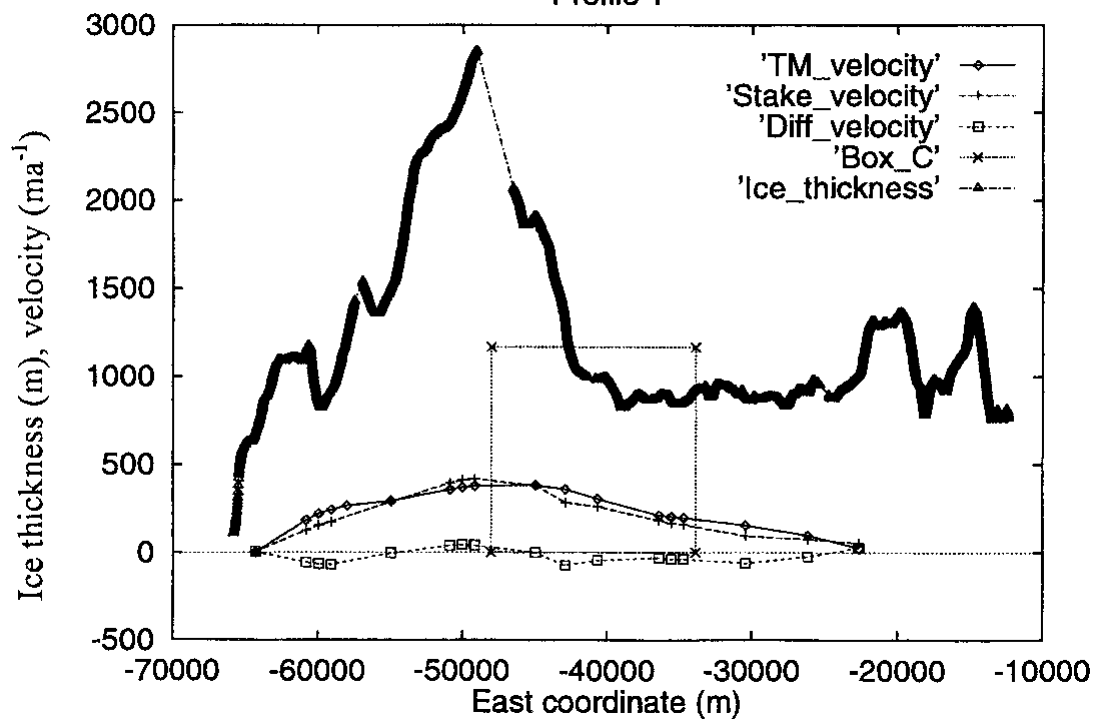

Fig. 3. Ice thickness ( heavy line) and surface speed at transverse profile 1, between nunataks futulrora and Nashornkalvane. Speed derived from Landsat-TM images, and stake measurements by Hoydal (1996); the differences between these datasets are plotted. Ice thickness is from ground-penetrating radar. The up-glacier side of box $C$ is in stippled lines.

stake measurements. The maximum discrepancy is $-74 \mathrm{~m} \mathrm{a}^{-1}$, the mean value of the velocity differences is $-21 \mathrm{~m} \mathrm{a}^{-1}$ and $\sigma=$ $39 \mathrm{~m} \mathrm{a}^{-1}$. From crevasse tracking we measured a maximum of $383 \mathrm{~m} \mathrm{a}^{-1}$ at profile 1, which is somewhat less than Høydal's maximum of $419 \mathrm{~m} \mathrm{a}^{-1}$. The standard deviation of the differences with Høydal's measurements represents $10 \%$ of the fastest Landsat-TM velocity $\left(\sim 400 \mathrm{~m} \mathrm{a}^{-1}\right)$ along this profile. There are few crevasses in the profile 1 area. Gridded velocities are obtained by interpolation from up to $2.5 \mathrm{~km}$ away. Høydal measured large short-scale velocity variations on three strain nets on this profile, therefore large discrepancies between the datasets can be expected. This comparison to stake measurements leads to a standard error for the Landsat-TM-derived and interpolated velocity field of $39 \mathrm{~m} \mathrm{a}^{-1}$ where there are no crevasses.

Systematic errors are caused by inaccurate coregistration of the images. A systematic error does not affect the budget of force calculation which is based on gradients in velocity, but we include the assessment here for completeness. We achieved $\mathrm{rms}=10 \mathrm{~m}$ when determining the transformation for the coregistration. If recording geometries of images differ there will be an unsystematic error from inaccurate coregistration due to topographic distortions in the images, but because we have corrected the images geometrically this error should be zero. Other errors from the crevasse-tracking method are changed crevasse patterns and inaccurate sub-pixel determination of the position of the correlation peak, which in other studies have been found to contribute by $0.5-2$ pixels (Whillans and Tseng, 1995; Bindschadler and others, 1996). Orheim and Luchitta (1987) were able to conduct feature tracking in an image pair over a 10 year period. Our crevasse pattern seemed unchanged during the 1 year period. We consider the standard deviation of this error to be $\sigma_{u}=0.5 \mathrm{pixel} / \mathrm{epoch}$-interval $\left(\sigma_{u}=14.25 \mathrm{~m} \mathrm{a}^{-1}\right)$. The absolute error is $\sigma_{a}=\sqrt{\sigma_{s}^{2}+\sigma_{u}^{2}}=17.41 \mathrm{~m} \mathrm{a}^{-1}$, where crevasses are present.

\section{Ice thickness from radar}

Bedrock was mapped from a helicopter flying $30-50 \mathrm{~m}$ above the surface along a $\sim 250 \mathrm{~km}$ longitudinal profile (profile 3, Fig. 2) and two transverse profiles (profile 1 is $75 \mathrm{~km}$ long and profile 2 is $23.5 \mathrm{~km}$ long) (Melvold, 1997; Näslund, 1997).
A ground-penetrating synthetic-pulse continuous-wave radar (Hamran and Aarholt, 1993) that transmits and receives electromagnetic waves in steps of 210 frequencies was used. Frequencies are evenly distributed over an adjustable bandwidth that can be set on the range from $300 \mathrm{kHz}$ to $3 \mathrm{GHz}$. The following information about the radar measurements is taken from Näslund (1997). Output signal was amplified to $150 \mathrm{~W}$, and dipole antennas with centre frequency of $158 \mathrm{MHz}$ were used. To map bedrock, the bandwidth was set to $5 \mathrm{MHz}(157-162 \mathrm{MHz})$, so that the signal theoretically could reach $3400 \mathrm{~m}$ deep. The sampling interval was $0.8-$ $1.0 \mathrm{~s}$ on the longitudinal profile and $0.4 \mathrm{~s}$ on the transverse profiles. A flying speed of 70-100 knots gave samples every 40-50 m for profile 3 and every $20 \mathrm{~m}$ for profiles 1 and 2 .

Helicopter positions derive from kinematic GPS measurements, conducted and processed by the Department of Mapping, Norwegian Polar Institute (Barstad and others, 1997). Dual-frequency Ashtech Z-XII geodetic GPS receivers were positioned on two ground-control points on the surrounding nunataks Brekkerista and Sørhausane, which yielded a baseline never $<100 \mathrm{~km}$ from the closest reference and a maximum of $140 \mathrm{~km}$ from the most remote reference during the flight. A third receiver was mounted on the helicopter. After data processing, the radar profiles were positioned with $1 \mathrm{~m}$ accuracy (Näslund, 1997).

GPS-navigation results and radar profiles were linked using relative time. Positions of the bed in the digital-radar data were determined by Melvold (1999) and there was little ambiguity. He estimated the ice-thickness error at $50 \mathrm{~m}$.

Results from radar measurements are shown in Figures 3 and 4 . For profile 1 the maximum ice thickness is $2800 \mathrm{~m}$ in a deep trough between the nunataks Nashornkalvane and Jutulrøra. East of the deep trough is a plateau approximately $1000 \mathrm{~m}$ deep (Fig. 3). Along profile 2 the bed is deepest on the west side, with a maximum ice thickness of $1300 \mathrm{~m}$. Thickness decreases about $200 \mathrm{~m}$ towards the east side (Fig. 4).

\section{Surface elevation}

The glacier-surface elevation points were measured by GPS as described for the radar measurements. Each point was 
Profile 2

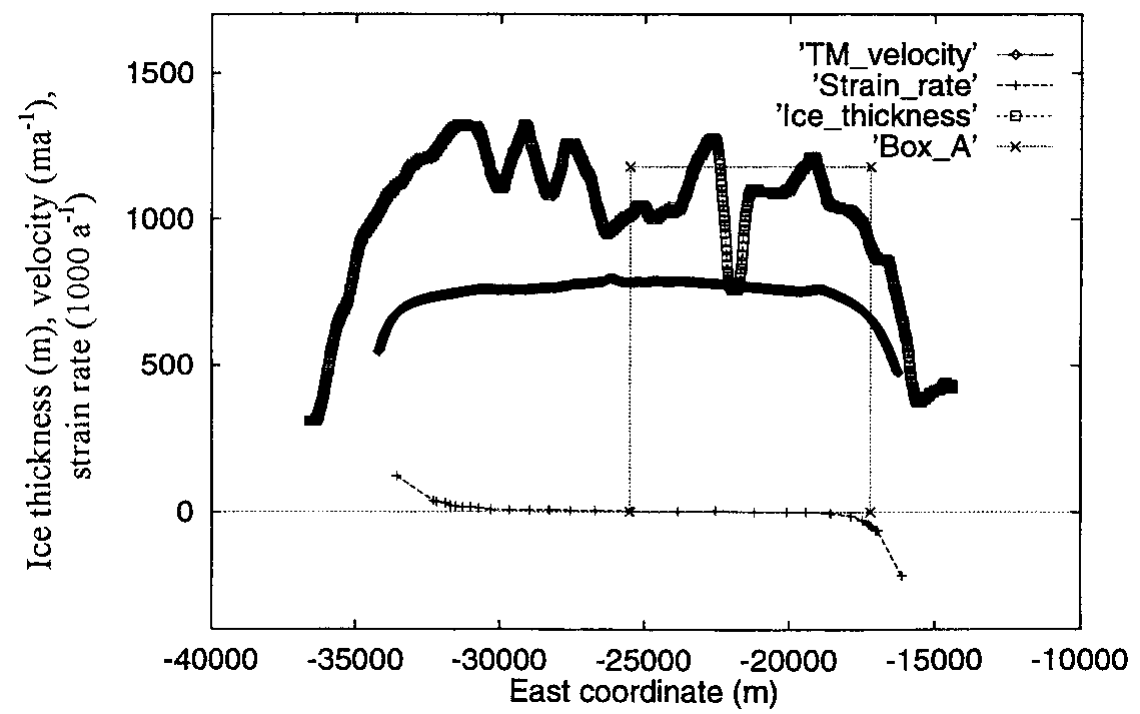

Fig. 4. Ice thickness ( heavy line), strain rates and surface speed at transverse profile 2, close to the grounding line. Speed is derived from Landsat-TM images, strain rates from interferometric SAR and ice thickness from ground-penetrating radar. The up-glacier side of box $A$ is in stippled lines.

measured over a $10 \mathrm{~s}$ interval at a sampling rate of $1 \mathrm{~s}$. The standard deviation of elevation error after processing is $0.05 \mathrm{~m}$. In addition there is a $0.19 \mathrm{~m}$ uncertainty in antenna height on the helicopter relative to the snow surface. The total uncertainty is $0.2 \mathrm{~m}$.

\section{APPLICATION OF FORGE BUDGET}

Høydal (1996) calculated temperature throughout the ice thickness based on surface measurements of temperature and modelling along profile 1 . His example for a $900 \mathrm{~m}$ thick section is representative for sections in our boxes. The temperature is much higher in the lowest $150 \mathrm{~m}$ (std error $85 \mathrm{~m}$ ). This warm ice is weaker and less likely to contribute substantially to the budget of forces. The mean temperature of the ice above the lowest $150 \mathrm{~m}$ thick ice is $-19^{\circ} \mathrm{C}$.

The rate factor at $-19^{\circ} \mathrm{C}$ is $B=500(50) \mathrm{kPa}^{1 / 3}$ (Hooke, 1998). We increase the uncertainty to $100 \mathrm{kPa}^{1 / 3}$ to account for uncertainty in temperature.

The effective ice thickness was calculated as $H^{\prime}=$ $H-150 \mathrm{~m}$, based on the work by Høydal (1996). The uncertainty in $H^{\prime}$ comes from uncertainty in ice thickness and in determining the thickness of the soft bottom layer. This leads to a total uncertainty of effective thickness of $100 \mathrm{~m}$.

\section{Selection of boxes}

Several criteria were included in selecting boxes. The boxes should be placed where there are sufficient measured strain rates to estimate the mean value of the stress on each side. Boxes should cover sections that are glaciologically interesting. Accurate elevations are necessary for the boxes, since incorrect surface slopes give large errors in the driving stress, and therefore inaccurate determination of the relative role of the driving and basal forces. The boxes were placed in along-flow positions where accurate GPS measurements of elevation and length of the box, $L$, were available.

Our three boxes cover from one-third to one-half of the eastern side of the glacier (Fig. 2); the grounding-line area and $\sim 65 \mathrm{~km}$ further up-glacier.

The east and the west sides of the boxes are placed where $\dot{\varepsilon}_{y x}$ are well determined. The western sides of the boxes are placed along the central flowline because the shear strain rates, $\dot{\varepsilon}_{y x}$, are zero. The central flowline was determined from the velocity field from Landsat and the fringe pattern in the interferogram. The eastern sides of boxes A and B were placed within the high shear zone as identified in the interferogram and in the coherence image (Fig. 5).

\section{Strain rates}

Strain rates were calculated from the gridded Landsat-TM velocity data (spacing $0.5 \mathrm{~km}$ ). The longitudinal strain rates, $\dot{\varepsilon}_{y y}$, were calculated over distances of $20 \mathrm{~km}$ and shear strain rates, $\dot{\varepsilon}_{y x}$, over distances of $10 \mathrm{~km}$. We assume the poorest accuracy of the velocity $\left(39 \mathrm{~m} \mathrm{a}^{-1}\right)$ when calculating errors. Along each side of the boxes, $10-20$ values (each $\sim 2.5 \mathrm{~km}$ ) of strain rates were derived from the appropriate grid, and average strain rates $\overline{\dot{\varepsilon}}_{y y}$ and $\overline{\dot{\varepsilon}}_{y x}$ are listed for all boxes in Table 1 .

A different approach was taken for the along-flow side of box A. Since the Landsat-TM velocity data do not cover the shear margin in that area, we used a European Remotesensing Satellite (ERS)-1 three-day repeat-pass interferogram (Fig. 1) to derive $\overline{\dot{\varepsilon}}_{y x}$ along profile 2 (Fig. 4), which is the down-glacier part of box A. The interferogram was processed by the Norwegian Defence Research Establishment (Andersen and others, 1998; Eldhuset and others, 1998). From the interferogram we found $\dot{\varepsilon}_{y x}=0.05 \mathrm{a}^{-1}$ at the down-glacier side, and $\dot{\varepsilon}_{y x}=0.03 \mathrm{a}^{-1}$ was extrapolated from the Landsat-TM data for the up-glacier side. Since the entire length of box A is placed in the high-shear margin (Fig. 5), we assume that the shear stress increases linearly downglacier and therefore can be described by two values.

\section{Results from force budget}

Stresses given by Equations (4), (5) and (8) were calculated from all the measured strain rates. Average stresses were used when calculating forces, and the stresses with uncertainties are listed in Table 2. Basal drag, $\tau_{\text {by }}$, was calculated from the force budget, Equation (2), and the results in Table 3.

Table 3 lists the values calculated using the force budget 


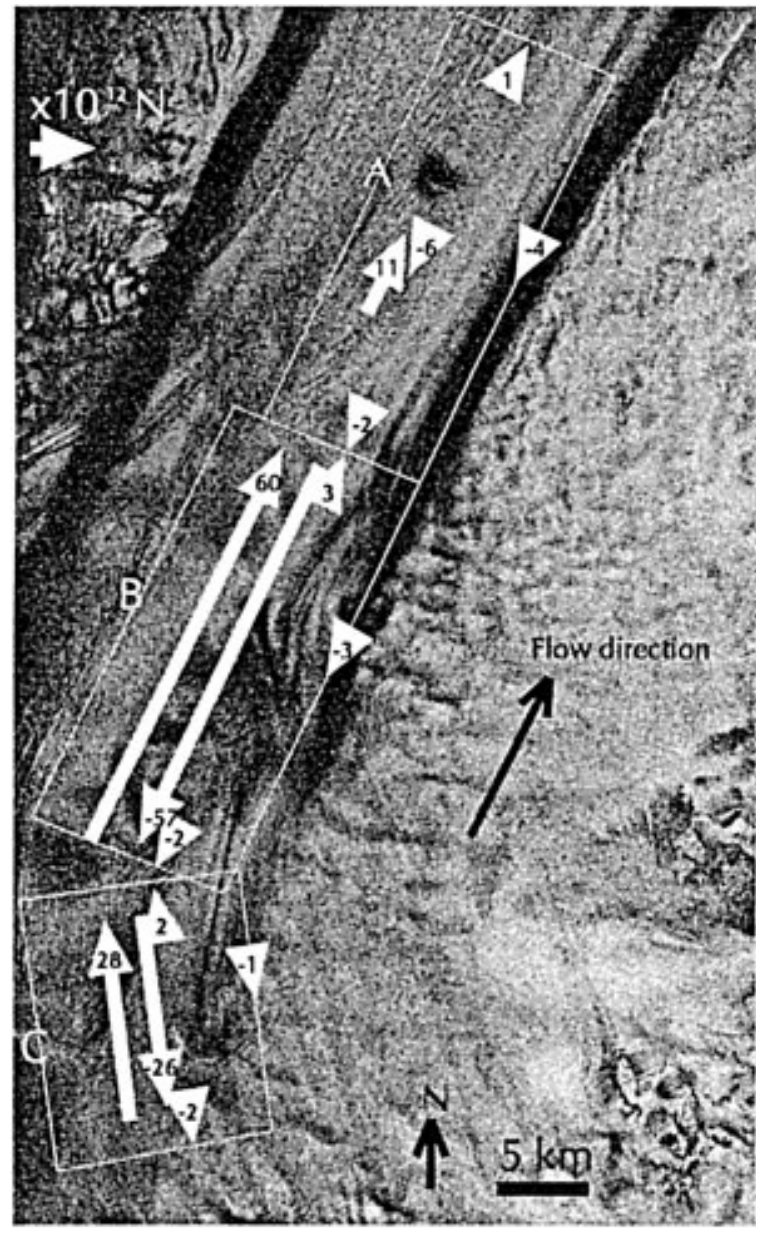

Fig. 5. Forces calculated for boxes $A, B$ and $C$. The units of the numbers are $10^{12} \mathcal{N}$. Background is the coherence image processed from ERS-1 data.

(Equation (2)). Forces are also given as percent of $F_{\mathrm{d} y}$. Results from the force budget are illustrated in Figure 5.

The role of the lateral drag is important for section A where it represents $38(17) \%$ of $F_{\mathrm{d} y}$, but for the grounded sections $\mathrm{B}$ and $\mathrm{C}$ it represents only $5(2) \%$ of $F_{\mathrm{d} y}$. Basal friction supports only half the driving stress in section A, where surface slope and driving stress are small. This section of the glacier must be partly floating, basal friction is small and flow is controlled by lateral drag from the shear margins. The force balance in section A is similar to that found for the ice streams feeding Ross Ice Shelf (Jackson and Kamb, 1997; Whillans and van der Veen, 1997), since ice is sliding on a low-friction bed and flow is controlled by shear stresses exerted from the mar-

Table 1. Measurements and average strain rates for sides of boxes (with uncertainties in parentheses)

\begin{tabular}{llrrr}
\hline & & \multicolumn{1}{c}{ Box A } & \multicolumn{1}{c}{ Box B } & \multicolumn{1}{c}{ Box $C$} \\
\hline Length $(\mathrm{m})$ & $L$ & $24434(0.05)$ & $24968(0.05)$ & $14794(0.05)$ \\
Width $(\mathrm{m})$ & $W$ & $8700(0)$ & $11200(0)$ & $12200(0)$ \\
Ice thickness $(\mathrm{m})$ & $\bar{H}$ down-glacier & $1040(54)$ & $1316(54)$ & $1349(54)$ \\
Ice thickness $(\mathrm{m})$ & $\bar{H}$ up-glacier & $1316(54)$ & $1349(54)$ & $987(54)$ \\
Elevation $(\mathrm{m})$ & $z$ down-glacier & $138.9(0.2)$ & $258.8(0.2)$ & $705.8(0.2)$ \\
Elevation $(\mathrm{m})$ & $z$ up-glacier & $258.8(0.2)$ & $705.8(0.2)$ & $920.3(0.2)$ \\
Strain rate $\left(10^{-3} \mathrm{a}^{-1}\right)$ & $\overline{\dot{\varepsilon}}_{y x}$ east side & $40.0(2.8)$ & $10.3(2.8)$ & $9.1(2.8)$ \\
Strain rate $\left(10^{-3} \mathrm{a}^{-1}\right)$ & $\bar{\varepsilon}_{y y}$ down-glacier & $3.8(2.8)$ & $8.5(2.8)$ & $3.5(2.8)$ \\
Strain rate $\left(10^{-3} \mathrm{a}^{-1}\right)$ & $\overline{\dot{\varepsilon}}_{y y}$ up-glacier & $8.5(2.8)$ & $3.8(2.8)$ & $10.0(2.8)$ \\
& & & & \\
\hline
\end{tabular}

Table 2. Stresses computed from numbers in Table 1 (with estimated uncertainties in parentheses)

\begin{tabular}{lrrr}
\hline Stress & Box A & Box B & Box C \\
& $\mathrm{kPa}$ & $\mathrm{kPa}$ & $\mathrm{kPa}$ \\
\hline $\bar{R}_{y y_{\text {east }}}$ & $169(34)$ & $101(20)$ & $89(18)$ \\
$\bar{R}_{y y_{\text {down-glacier }}}$ & $154(32)$ & $215(43)$ & $151(33)$ \\
$\bar{R}_{y y_{\text {up }} \text { glacier }}$ & $215(43)$ & $161(34)$ & $222(45)$ \\
$\bar{R}_{y y_{\text {diff }}}$ & $61(61)$ & $54(68)$ & $40(70)$ \\
$\bar{\tau}_{\mathrm{d} y}$ & $52(2)$ & $214(8)$ & $152(7)$ \\
$\bar{\tau}_{\text {by }}$ & $25(10)$ & $205(10)$ & $138(9)$ \\
\hline
\end{tabular}

Table 3. Calculated forces (with estimated uncertainties in parentheses). Comparison to driving force is given as per cent of driving force. Negative values indicate resistance to the driving stress

\begin{tabular}{lrrrrrr}
\hline Forces & \multicolumn{2}{c}{ Box $A$} & \multicolumn{2}{c}{ Box $B$} & \multicolumn{2}{c}{ Box $C$} \\
& $10^{12} \mathrm{~N}$ & $\%$ & $10^{12} \mathrm{~N}$ & $\%$ & $10^{12} \mathrm{~N}$ & $\%$ \\
\hline$F_{\mathrm{d} y}=L W \tau_{\mathrm{d} y}$ & $11.0(0.5)$ & 100 & $60.0(2.2)$ & 100 & $27.5(1.2)$ & 100 \\
$L H^{\prime} R_{x y_{\text {diff }}}$ & $-4.2(1.9)$ & -38 & $-3.0(1.3)$ & -5 & $-1.3(0.6)$ & -5 \\
$W H^{\prime} R_{y y_{\text {diff }}}$ & $-1.0(0.6)$ & -9 & $0.6(1.0)$ & 1 & $0.1(1.0)$ & 0 \\
$F_{b y}$ & $-5.8(2.1)$ & -53 & $-57.6(2.7)$ & -96 & $-26.0(1.7)$ & -95 \\
\hline
\end{tabular}

gins. The cases differ since basal drag at Ice Stream B is $\sim 2 \mathrm{kPa}$, compared to $\sim 25 \mathrm{kPa}$ at Jutulstraumen.

Differential longitudinal forces play a small role for all sections, and especially for both of the grounded upper sections. Calculated differential forces are small and smaller than the uncertainties. Considering estimated uncertainties and forces, there is confidence in longitudinal forces being $9(6) \%$ of $F_{\mathrm{d} y}$ for box A and $0(4) \%$ of $F_{\mathrm{d} y}$ for grounded sections B and C. Small differential longitudinal force compared to the basal drag is in agreement with what has been modelled for ice sheets by Alley (1984) and Lingle and Troshina (1998). Alley found that longitudinal stresses increase towards the coast, yet are less than $1 \%$ of the basal shear stress.

Driving stress and basal shear are large for both grounded sections B and C, but largest for the midsection $\mathrm{B}$. Surface slope in section B is 1 and average ice-thickness is $1332 \mathrm{~m}$, and for section C slope is 0.8 and average ice thickness is $1168 \mathrm{~m}$. The large basal friction found in the mid-section may be due to a $\sim 300 \mathrm{~m}$ peak in the bed topography in the middle of section $\mathrm{B}$ in flow direction.

The grounding-line position has not been determined accurately for Jutulstraumen. Where the glacier is floating the basal friction must be zero. We found $\tau_{\mathrm{b} y}=25 \mathrm{kPa}$ for section $\mathrm{A}$, but this is an average value for the entire section. Since the results show some basal friction in section A, we suggest that the grounding line is in the section, but farther up-glacier than profile 2 .

\section{Contributions to uncertainties}

The relative importance of the forces for a box determines which measurement uncertainty is critical to the calculations. For the grounded sections (box B and $\mathrm{C}$ ) more than $95 \%$ of the driving force is balanced by basal friction. Driving stress and driving force are described by Equations (8) and (9). The measurement uncertainties involved in these 
equations are in average ice thickness and surface elevation. Error propagation of the driving force showed that uncertainty in average ice thickness contributed $>97 \%$ of the estimated uncertainty in the basal force.

For box A, 38\% of the driving force is balanced by lateral force. In this floating section, the main contribution to the uncertainty in the basal force is from the lateral force. Lateral force and stress are given by Equations (2) and (4). Measurement uncertainties are from the velocities used for strain rates and the rate factor in Glen's flow law. The error propagation showed that the rate factor contributed $>85 \%$ of the uncertainty in the basal force.

The largest uncertainty in basal force is found for box A, representing $19 \%$ of the driving force, whereas the uncertainty is only $5 \%$ for box $\mathrm{B}$, and $6 \%$ for box $\mathrm{C}$. Repeat measurements will reduce the mean uncertainties of the forces calculated from stresses. Uncertainty in shear stresses can be reduced by more observations of the strain rates in the interferogram. This would reduce the uncertainty in the basal force in particular for section A. More GPS elevation and ice-thickness measurements are necessary to reduce the mean uncertainty of the driving stresses for all boxes.

\section{Position and dimensions of boxes}

Because stresses vary over the glacier, the results can be sensitive to the position and size of the boxes selected. Forces were calculated from the range of measured stresses $R_{y x}$ and $R_{y y}$ over the sides for each box. We found that stress variation over the sides would yield force variation representing a maximum of $8 \%$ of $F_{\mathrm{d} y}$ for each box. The final result can therefore be somewhat different if the section was separated into smaller boxes where $\bar{R}_{y x}$ and $\bar{R}_{y y}$ have other values. Additional measurements of surface elevations for driving stress are needed to conduct a force budget for smaller boxes.

\section{GONGLUSIONS}

The strain rates calculated from remotely sensed velocity data are sufficiently accurate for a large-scale force budget, and can be used for a detailed study of the mechanics of Jutulstraumen. The accuracy of the dataset as a whole is adequate to determine that longitudinal and lateral forces play a minor role in controlling ice flow for the grounded part of Jutulstraumen studied. For the floating part, lateral drag is important as resistance to flow. The main limitation of the dataset lies in the uncertainty of ice thickness for determining driving stress for the grounded part, and uncertainty in the rate factor for determining lateral stresses for the floating part. Since average stresses are considered for the large-scale force budget, uncertainties given by the mean error of the stresses can be reduced by repeating necessary measurements. For lateral stress this can be done by deriving more strain rates from the interferogram. For the driving stress, accurate GPS measurements of glacier-surface elevations and ice thickness are necessary.

\section{ACKNOWLEDGEMENTS}

C. J. van der Veen contributed with helpful comments on the manuscript. We thank the Norwegian Defence Research Establishment for processing of the ERS-1 SAR data. The
"Monitoring Ice Velocities in Jutulstraumen, Antarctica" project was funded by the Norwegian Research Council.

\section{REFERENCES}

Alley, R. B. 1984. A non-steady ice-sheet model incorporating longitudinal stresses: application to the adjustment of interior regions of an ice sheet to changes in sea level. Ohio State Univ. Inst. Polar Stud. Rep. 84.

Alley, R. B. and I. M. Whillans. 1984. Response of the East Antarctica ice sheet to sea-level rise. 7. Geophys. Res., 89(C4), 6487-6493.

Andersen, P. H., K. Aksnes and H. Skonnord. 1998. Precise ERS-2 orbit determination using SLR, PRARE, and RA observations. f. Geod., 72, 421-429.

Bamber, J. L. and R. A. Bindschadler. 1997. An improved elevation dataset for climate and ice-sheet modelling: validation with satellite imagery. Ann. Glaciol., 25, 439-444.

Barstad, B., T. Eiken, R. Finnes and O. Øvstedal. 1997. Geodetic measurements in Dronning Maud Land. In Report of the Norwegian Antarctic Research Expedition 1996/97. Oslo, Norwegian Polar Institute, 67-76. (Report 148.)

Bevington, P. R. and D. K. Robinson. 1992. Data reduction and error analysis for the physical sciences. Second edition. New York, McGraw-Hill Inc.

Bindschadler, R., P. Vornberger, D. Blankenship, T. Scambos and R. Jacobel. 1996. Surface velocity and mass balance of Ice Streams D and E, West Antarctica. 7. Glaciol., 42(142), 461-475.

Eldhuset, K. and 6 others. 1998. ERS tandem INSAR processing for DEM generation and glacier motion estimation. In Proceedings of the 27th International Symposium on Remote Sensing of the Environment, 8-12 June 1998, Tromsø, Norway. Ann Arbor, MI, Environmental Research Institute of Michigan, $579-582$.

Gjessing, Y. T. 1972. Mass transport of Jutulstraumen ice stream in Dronning Maud Land. Nor. Polarinst. Arbok 1970, 227-232.

Hamran, S.-E. and E. Aarholt. 1993. Glacier study using wavenumber domain synthetic aperture radar. Radio Sci., 28(4), 559-570.

Hooke, R. LeB. 1998. Principles of glacier mechanics. Upper Saddle River, NJ, Prentice Hall.

Høydal, Ø. А. 1996. A force-balance study of ice flow and basal conditions of Jutulstraumen, Antarctica. F. Glaciol., 42(142), 413-425.

Jackson, M. and B. Kamb. 1997. The marginal shear stress of Ice Stream B, West Antarctica. 7. Glaciol., 43(145), 415-426.

Lingle, C. S. and E. N. Troshina. 1998. Relative magnitudes of shear and longitudinal strain rates in the inland Antarctic ice sheet, and response to increasing accumulation. Ann. Glaciol., 27, 187-193.

Melvold, K. 1999. Impact of recent climate on glacier mass balance: studies of Kongsvegen, Svalbard and Jutulstraumen, Antarctica. (D.Sc. thesis, University of Oslo.) (Department of Geography Report 13.)

Melvold, K., J. O. Hagen, T. Laumann and C. Rolstad. 1997. Mass balance and dynamics on Jutulstraumen ice stream. In Report of the Norwegian Antarctic Research Expedition 1996/97. Oslo, Norwegian Polar Institute, 118-124. (Report 148.)

Näslund, J.-O. 1997. Airborne radar soundings of ice depths, GPS measurements of ice velocity and studies of landform evolution in central Dronning Maud Land, East Antarctica. In Report of the Norwegian Antarctic Research Expedition 1996/97. Oslo, Norwegian Polar Institute, 125-136. (Report 148.)

Orheim, O. and B. K. Lucchitta. 1987. Snow and ice studies by Thematic Mapper and multispectral scanner Landsat images. Ann. Glaciol., 9, 109-118.

Rolstad, C., J. Amlien, J. O. Hagen and B. Lundén. 1997. Visible and nearinfrared digital images for determination of ice velocities and surface elevation during a surge on Osbornebreen, a tidewater glacier in Svalbard. Ann. Glaciol., 24, 255-261.

Scambos, T. A., M. J. Dutkiewicz, J. G. Wilson and R. A. Bindschadler. 1992. Application of image cross-correlation to the measurement of glacier velocity using satellite image data. Remote Sensing Environ., 42(3), 177-186.

Van Autenboer, T. and H. Decleir. 1978. Glacier discharge in the Sør-Rondane, a contribution to the mass balance of Dronning Maud Land, Antarctica. Z. Gletscherkd. Glazialgeol., 14(1), 1-16.

Van der Veen, C. J. and I. M. Whillans. 1989. Force budget: I. Theory and numerical methods. f. Glaciol., 35(119), 53-60.

Whillans, I. M. and C. J. Merry. In press. Analysis of the shear zone at the western side of the Ross Ice Shelf using satellite imagery. Cold Reg. Sci. Technol.

Whillans, I. M. and Y.-H. Tseng. 1995. Automatic tracking of crevasses on satellite images. Cold Reg. Sci. Technol., 23(2), 201-214.

Whillans, I. M. and C. J. van der Veen. 1993. Patterns of calculated basal drag on Ice Streams B and C, Antarctica. F. Glaciol., 39(133), 437-446.

Whillans, I. M. and C. J. van der Veen. 1997. The role of lateral drag in the dynamics of Ice Stream B, Antarctica. 7. Glaciol., 43(144), 231-237. 